\title{
An Approach for Power Quality Enhancement using Y Source Inverter Clubbed with Active Filtration
}

\author{
Ishani Sharma \\ M.tech Scholar, Department of Electrical Engineering \\ D.A.V Institute of Engineering and Technology \\ Jalandhar, India
}

\author{
Baljit Singh \\ Assistant Professor, Department of Electrical Engineering \\ D.A.V Institute of Engineering and Technology \\ Jalandhar, India
}

\begin{abstract}
Power is essential to drive all the electrical appliances. Power quality has a significant role in electronic devices. However, with the development in the electronics industry, the problem of poor power quality has also risen at the same time. The devices used nowadays are quite sensitive to the fluctuations in power. Various problems faced in power quality are voltage swell, sag, short interruptions, distortions, etc. Various methods had been proposed in the past for mitigating the power quality problems. Conventionally, Voltage source inverter (VSI) was used in Dynamic voltage restorer (DVR). This gave rise to the introduction of harmonics in the system signal and was not much efficient. So in this paper, a DVR based system associated with the $\mathrm{Y}$-source inverter is proposed to mitigate the voltage sag issue. The system is analyzed with both the active and passive filters. Fault is inserted externally in the system for estimating the harmonics level in the system. The total harmonics distortion (THD) parameter is taken for determining the performance of the system. The suggested system is simulated on the MATLAB software. From these results, it is verified that the proposed system outperforms the other traditionally used techniques for eliminating the voltage sag.
\end{abstract}

Keywords-Power Quality, DVR, Y-source inverter, passive and active filters, voltage sag

\section{INTRODUCTION}

Power quality measures the fitness of electric power transmitted from the utilities to the industrial, commercial and domestic consumers from the point of centralized generation or in the case of distributed generation it may be from the consumers to utilities.

Power quality can be defined as an electrical boundary set that permits the equipment to function deliberately without affecting the performance or the life expectancy. Recently more attention has been focused on the power quality domain in power system networks due to the increase in the number of sensitive equipment, disturbances introduced by the non-linear loads and the proliferation of renewable energy sources. Power quality relevant issues are the main concern in the modern era. The different power quality issues are:

- Voltage sag

- Voltage swell

- Short interruptions

- Long interruptions

- Harmonic distortion

- Voltage spike

- Noise

- Voltage fluctuation

- Voltage unbalance
Nearly $50 \%$ of all power quality disturbances are related to voltage quality type.

In various countries, the surveys and case studies have been done for estimating the impacts of poor PQ to users and by studying these surveys it has been founded that Voltage sags are regarded as most severe disturbances which affect power quality in power system because these disturbances affect both the utilities and the consumers.

In order to mitigate these power quality issues, custom device DVR is used.

DVR is a device that helps connecting in series for reducing the effects of instabilities in the distribution network [1]. They are able of maintaining the voltage at a small amount of magnitude and phase by compensating the voltage sag/swell, the voltage imbalance and the voltage harmonics faced at the same coupling point [2] [3]. These systems surpass the voltage sag by enhancing the suitable voltage in series with supply voltage and avoid the power loss.

In 1994, L.Gyugyi suggested a suitable instrument and technique for restoring the utility distribution network [4]. This technique uses the real power for eliminating the effects of a power failure and it is commonly called dynamic voltage restorer. This DVR must be prepared to react as quickly as possible to insert the missing voltage in scheme because of the sensitivity of delicate loads to voltage modifications. It is a condition-based PWM-modulated voltage source inverter that produces or absorbs actual or reactive power. Voltage sag is induced by non-symmetrical line-to-line, line ground, and double-line-to-ground and symmetrical 3-phase faults due to load sensitivity. The DVR offers autonomous voltage loads to restore and retain the sensitivity to its nominal value. The diagram of conventional DVR configuration is represented in fig. 1 .

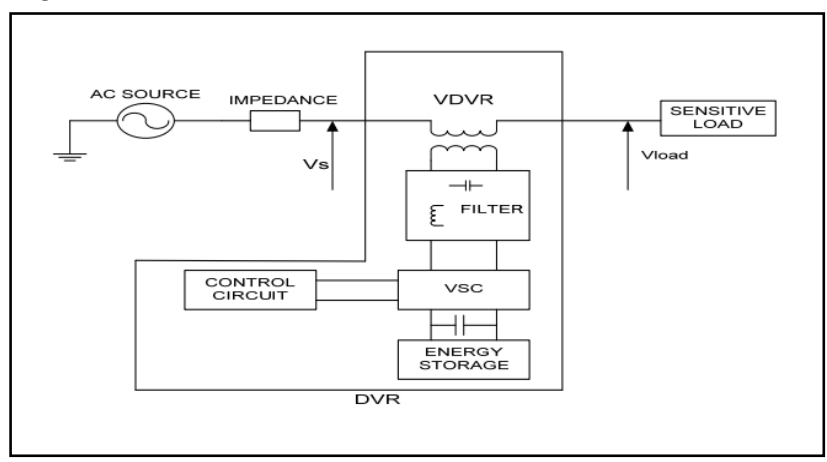

Fig. 1: Conventional Circuit Configuration 
Various researchers have used DVR for mitigating voltage sag and voltage swell issues in the system. Some of these proposed approaches are discussed in the next section:

\section{LITERATURE REVIEW}

DVR is the proficient and custom power system that is very compelling in smothering the voltage swell/lists issues. Therefore, it has been used by a number of researches.

In the paper [2] dynamic voltage restorer was utilized for remunerating the droops in voltage and sounds. Arrangement converter was given to the line side and the shunt was connected to the appliance or load side.

In paper [5], two devices were designed namely DVR and distribution static compensator, one in series and latter was connected in shunt. DVR protects the power system from the sag/swells and DSTATCOM saves the system from flickering production in the load.

The author in [6] discussed the different DVR control techniques and their configuration.

Author of paper [7] had talked about the DVR framework for repaying the unstable voltage droops and sounds which more often seen during $3 \mathrm{~s}$ to $1 \mathrm{~min}$. In the proposed model, the neural system control framework and PWM had been utilized.

In paper [8] various strategies for taking care of the power quality issues had been recommended.

In [9] a comparison between PWM based PI control and Hysteresis voltage control scheme for the production of pulses related to the DVR is done. Controlling and compensation techniques specifically focused on compensating with accuracy and fast response having low cost.

A brief introduction about the issues related to power quality was given in paper [10]. This paper also provided information about the compensation techniques using DVR.

The paper [11] described the effective use of DVR for power distribution systems in voltage sag and swell elimination. The DVR proposed in the paper is based on the DQO concept. The suggested model was quite effective in managing the distribution system problems.

An advanced phase multi-loop control technique is used for increasing the voltage transformation feature of the device in paper [12].

In paper [13], it is described that DVR is a quite efficient device which works on the principle of voltage source inverter (VSI). VSI inserts the suitable voltage in series to system voltages for reducing the effect of variations in voltage in distribution feeder lengths.

The author in paper [14] had proposed a MATLAB simulation model having a DVR with a hysteresis controller as the voltage sag/swell reducing device in the electrical and electronics power distribution systems. It is considered an efficient technique; however, in this, the harmonics are not reduced to a high extent.

\section{PRESENT WORK}

It has been analyzed that in order to achieve quality power, the previous work uses DVR that helps to reduce various PQ issues. But in this, the harmonics are not reduced to a high extent and also the power quality is not much sufficient.

In the traditional work, in DVR the VSI was used to invert the dc which is supplied by the energy storage device. The rating of an inverter is relatively high in current and low in voltage due to the utilization of the step-up injection transformer. However, in order to reduce the PQ issues, it is required to upgrade the inverter which consists of high voltage that will help to enhance the quality of power.

Therefore, various previous studies were analyzed and it is founded that $y$-source inverters are efficient inverters. Such as, in [13], the y-source inverter was used to interface PV array and in this paper, it has been stated that the flexibility and the performance of this inverter are supreme as compared to the inverters present in the market. Unlike traditional multilevel inverters, it has less number of switches due to which the switching losses are less. Also, from [15] it has been studied that Y -Source inverter is able to produce a very high voltage gain while simultaneously operating at a higher modulation index and it can reduce the component count, lowers the switching device stress, better utilizes the input voltage and improves the power quality; and finds niche in applications where a higher boost is required, e.g. in distributed generation. The paper [16] compared the Z-source Inverter and Y-source Inverter by using various controlling approaches related to these inverters and it has been analyzed that the increased voltage was attained at maximum modulation index and the minimum shoot-through duty ratio in case of $Y$-source inverter. And Voltage stress across switches was also lesser in $\mathrm{Y}$-source inverter as compared to Z-source inverter for the boosted output.

Therefore, from the analysis, it is observed that $y$-source inverters are the efficient inverters that are used in previous works for different applications; however, for the proposed application the y-source inverters are not used yet.

Therefore, the $y$-source inverter is used in the proposed work instead of Voltage Source Inverter and for different applications.

Also, in the conventional work (DVR) the passive filter was used to limit the harmonics and to improve the waveform of inverter towards sinusoidal. However, in the present work, the comparison analysis of passive and active filters is analyzed by which it is founded that active filters are superior to passive filters and can suppress supply current harmonics and also reactive power components. Active power filters comprise of power electric types of equipment and are capable to produce the particular current components for mitigating the harmonic currents which take place due to nonlinear loads. Moreover, active filters do not exhibit any insertion loss. So, the active filters are used in the proposed work. 
Thus, by enhancing the previous work, the power quality is enhanced in the distribution network which was the main objective of the proposed work.

\section{RESULTS AND DISCUSSIONS}

In the proposed work Y-source inverter and Conventional DVR are used, as they are efficient and mitigate harmonics in signals. DVR and Y-source inverter are applied for both the active and passive filters. Following are the results for the proposed work:

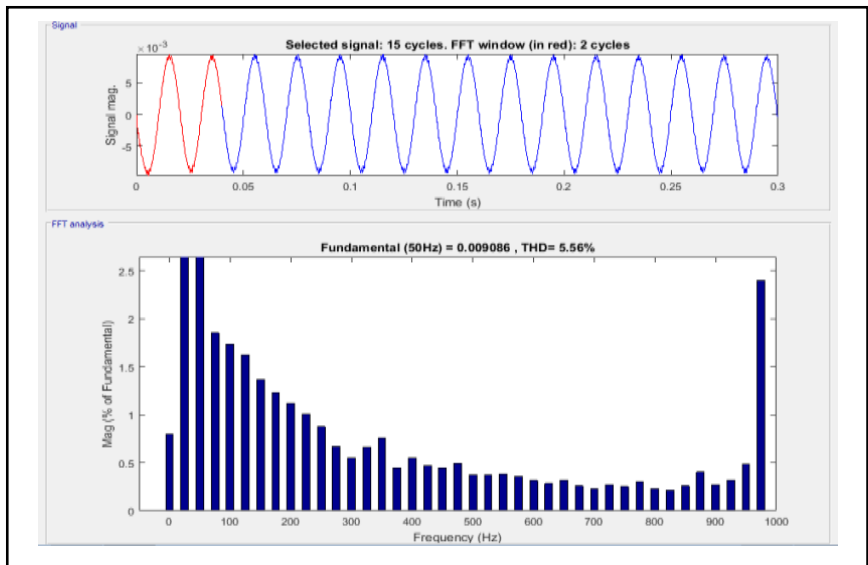

Fig. 2: Voltage sag and compensation using Passive filter

Fig. 2 illustrates the voltage signals without DVR and with DVR and passive filter. In the figure, voltage sag is observed from 0.1 to 0.2 in the absence of a DVR. This sag in voltage is eliminated when the passive filter and conventional DVR are employed.

Fig. 3 shows the output result of a passive filter in terms of FFT. The sample of the selected signal is similar to the signal selected for the active filter. Frequency is along the $\mathrm{x}$-axis and signal magnitude is along the $y$-axis. The fundamental frequency is 0.009086 . Total harmonics distortion i.e. THD is $5.56 \%$ in this case.

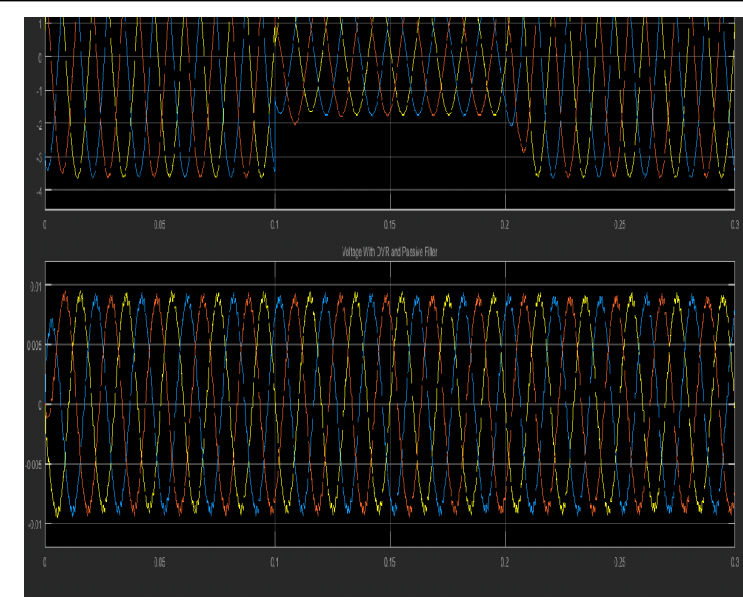

Fig. 3: Passive Filter Output

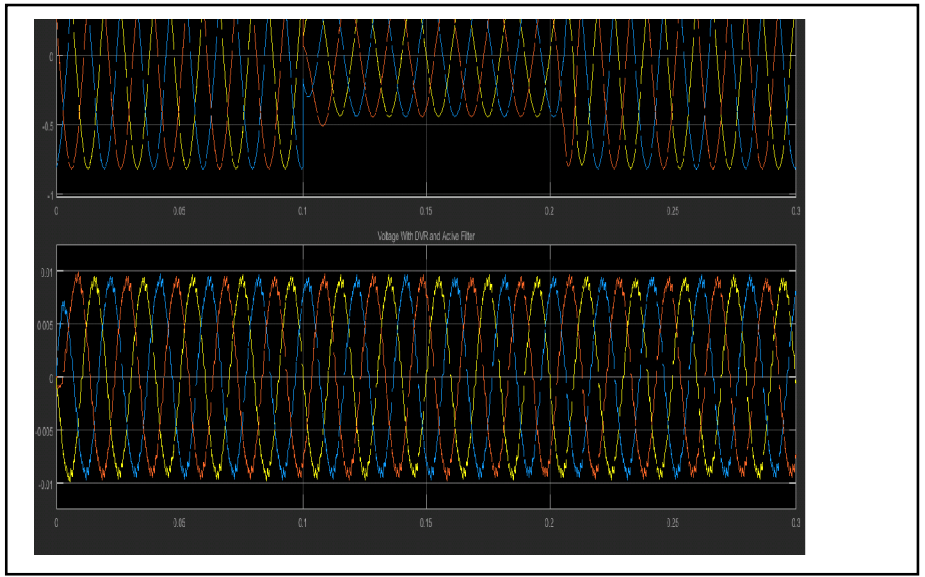

Fig. 4: Voltage sag and compensation Using Active Filter

Fig. 4 shows the voltage sag without using the DVR in the above section of the figure. It can be seen that voltage sag without using DVR is from 0.1 to 0.2 . This voltage sag is compensated (below section of fig. 4) using DVR and active filter and homogeneity in signal have been obtained.

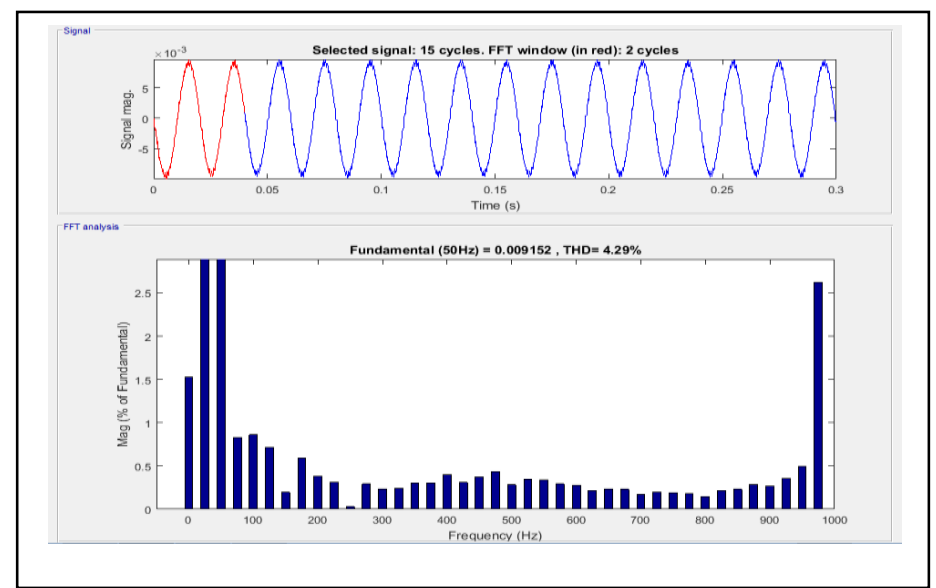

Fig. 5: Active Filter Output

Fig. 5 shows the results for the active filter and DVR for the selected signal. Signal is analyzed using FFT. The red color in the above diagram depicts 2 cycles. Frequency is shown along the $\mathrm{x}$-axis and the magnitude of fundamental is along the $\mathrm{y}$-axis. The frequency range is from 0 to 2000 and that of magnitude is 0 to 2.5 . Here the total harmonics distortion is $4.29 \%$.

\section{CONCLUSION AND FUTURE SCOPE}

Power Quality related issues are of most concern nowadays. Most of these problems are caused by the fluctuations in the voltage. Various researchers have continuously worked for mitigating these issues; however, they do not achieve a high power quality and also the harmonics exist in the system.

Thus, in this paper, Y-source inverter and DVR are employed for mitigating power quality problems. DVR and Ysource inverter are used for both the active as well as for the passive filters. This proposed system is analyzed using the simulation software MATLAB. A comparison is made on the basis of the magnitude of signal and total harmonic distortions (THD) form. From the analysis of the results, it was found that THD for the active filter using DVR is $4.26 \%$. On the other 
hand, THD for passive filter is $5.56 \%$ which is higher than the proposed system. This clearly indicates that the proposed system outperforms the traditionally available systems for mitigating the voltage sag.

In the future, along with the proposed system, the voltage swell, long interruptions, noise, etc. may also be considered for improvement.

\section{REFERENCES}

[1] Sang-Joon Lee, Hyosung Kim, Seung-Ki Sul and F. Blaabjerg, "A Novel Control Algorithm for Static Series Compensators by use of PQR Instantaneous Power Theory," in IEEE Transactions on Power Electronics, vol. 19, no. 3, pp. 814-827, May 2004

[2] Jowder, F.A.L, "Design and Analysis of Dynamic Voltage Restorer for Deep Voltage Sag and Harmonic Compensation", 2009.

[3] V. K. Ramachandaramurthy, A. Arulampalam, C. Fitzer, C. Zhan, M. Barnes and N. Jenkins, "Supervisory Control of Dynamic Voltage Restorers," in IEE Proceedings - Generation, Transmission and Distribution, vol. 151, no. 4, pp. 509-516, 11 July 2004.

[4] L. Gyugyi, C.D. Schauder, C.W. Edwards, M.Sarkozi, "Apparatus and Method for Dynamic Voltage Restoration of Utility Distribution Networks", U.S. Patent, Issue 1, Vol. 5, pp. 329-222, 1994.

[5] M. D. Stump, G. J. Keane and F. K. S. Leong, " The Role of Custom Power Products in Enhancing Power Quality at Industrial Facilities," Proceedings of EMPD '98. 1998 International Conference on Energy Management and Power Delivery (Cat. No.98EX137), Singapore, 1998, pp. $507-517$ vol. 2

[6] Rosli Omar, Nasrudin Abd Rahim, Marizan Sulaiman, "Dynamic Voltage Restorer Application for Power Quality Improvement in Electrical Distribution System: An Overview”, 2011, Australian Journal of Basic and Applied Sciences.

[7] T. K. Sahu and S. Gupta, "Neural Network Control for Power Quality Enhancement using Dynamic Voltage Restorer," 2nd IEEE International
Conference on Recent Trends in Electronics, Information \& Communication Technology (RTEICT), 2017, Pp. 1448-1452

[8] V. Kavitha and K. Subramanian, "Investigation of Power Quality Issues and its Solution for Distributed Power System," 2017 International Conference on Circuit ,Power and Computing Technologies (ICCPCT), Kollam, 2017, Pp. 1-6

[9] G. S. Dua and R. Kaur, "Enhancement of Power Quality in Distribution Network using DVR," 2015 Annual IEEE India Conference (INDICON), 2015, Pp. 1-6

[10] R. Pandya and F. Bhavsar, "Study on Compensation of Voltage Sag and Voltage Swell by Using DVR (Dynamic Voltage Restorer)," 2018 International Conference on Current Trends towards Converging Technologies (ICCTCT), Coimbatore, 2018, Pp. 1-4

[11] D. Francis and T. Thomas, "Mitigation of Voltage Sag and Swell using Dynamic Voltage Restorer," 2014 Annual International Conference on Emerging Research Areas: Magnetics, Machines and Drives (AICERA/iCMMD), 2014, Pp. 1-6

[12] Y. R. Ikhe and M. Upadyay, "Novel Control Method for Compensation of Voltage Sags and Swells using Dynamic Voltage Restorer," 2016 International Conference on Signal Processing, Communication, Power and Embedded System (SCOPES), Paralakhemundi, 2016, Pp. 59-62

[13] M. A. K. A. Biabani, Syed Mahamood Ali, Akram Jawed, "Enhancement of Power Quality in Distribution System using D-Statcom," 2016 International Conference on Signal Processing, Communication, Power and Embedded System (SCOPES), 2016, Pp. 2093-2098

[14] Santosh Kumar Singh, Sudhir Kumar Srivastava, "Enhancement in Power Quality using Dynamic Voltage Restorer (DVR) in Distribution Network", 2017.

[15] A. K. Sahoo and T. Thyagarajan, "Modeling of Facts And Custom Power Devices in Distribution Network to Improve Power Quality," International Conference on Power Systems, Kharagpur, 2009, Pp. 1-7

[16] S. Praveena and B. S. Kumar, "Performance of Custom Power Devices for Power Quality Improvement," 2017 IEEE International Conference on Power, Control, Signals and Instrumentation Engineering (ICPCSI) Chennai, 2017, Pp. 912-917 